\title{
España vista por José Marín Cañas ${ }^{1}$
}

\section{Gabriel Baltodano Román ${ }^{2}$} Universidad Nacional, Costa Rica

\section{RESUMEN}

La crónica ocupa un lugar fundamental en la obra literaria de José Marín Cañas, pues refleja la cercanía del lenguaje poético con medios como la publicación periódica. Este estudio analiza y comenta la obra Tierra de conejos (1971), libro de viajes por España. Se analizan, por una parte, el influjo de este autor en los géneros referenciales; por otra, la manera como construye una imagen de la cultura hispánica.

\begin{abstract}
Chronicles are an essential part of the work of José Marín Cañas, reflecting the closeness of poetic language with periodicals as means of communication. This study analyzes and comments on Tierra de conejos (1971), a travelogue about Spain. The influence of this author on referential genres is addressed, as is the way he constructs an image of Hispanic culture.
\end{abstract}

Palabras clave: literatura costarricense, crónica costarricense, libros de viajes.

Keywords: Costa Rican literature, literature, travel literature.

${ }^{1}$ Artículo elaborado a partir de conferencia en el Instituto Costarricense de Cultura Hispánica, leída el 23 de julio de 2008. Recibido: 10 de mayo de 2009; aceptado: 29 de junio de 2009.

${ }^{2}$ Correo electrónico: jgbaltodanor@ costarricense.cr 
Se abrió la puerta que tiene gonces en mi corazón,

y otra vez la galería de mi historia apareció.

Otra vez la plazoleta de las acacias en flor, y otra vez la fuente clara cuenta un romance de amor.

Antonio Machado, «Canciones de tierras altas» ${ }^{3}$

Entre el 7 de enero y el 10 de octubre de 1969, José Marín Cañas visitó buena parte de España. Su recorrido incluyó ciudades como Granada, Málaga, Cádiz, Algeciras, Sevilla, Córdoba, Madrid, Toledo, Segovia, Zaragoza y Barcelona. Entre caminos, múltiples comarcas, haciendas y poblados lo reciben y acogen; barrios como Albaicín, donde los perros mueven la cola vertical y no horizontalmente para evitar golpearse con las paredes, de estrechas que son las calles ${ }^{4}$. Los miradores como Lindajara ofrecen un descanso para el andariego; los ferrocarriles, un panorama.

En la mayoría de las ocasiones, el viaje le permite contemplar las maravillas casi olvidadas; su encuentro con Sevilla parece, ante los ojos del lector, el regreso a brazos de una antigua amada, «hembra de tronío», «Moruna y cristiana, se mira, como en un espejo roto, en las aguas escasas del Guadalquivir, que viene caminando desde Córdoba, refresca a la gitana y sigue para alimentar el océano, ignoto imperio, Mar Tenebroso, que vio los velámenes y sintió las quillas desde siglos, cuando el mundo entero andaba a ver dónde conseguía la canela, que en estas tierras la tienen en el alma, en las guitarras y los toreros» (80).

\footnotetext{
${ }^{3}$ Antonio Machado, Poesía. Introducción y selección de Jorge Campos (Madrid: Alianza, 1994) 123.

${ }^{4}$ José Marín Cañas, Tierra de conejos. Por caminos, pueblos y tumbas de España (Madrid: Anaya, 1971) 56. En adelante, se indica, entre paréntesis, el número de página.
} 
Esta evocación del idilio extraviado, de la partida y la distancia, hace que las visiones, aunque nuevas, resuenen a objeto del recuerdo. Córdoba ha perdido, para el narrador, los contornos fieles; se ha convertido en un «esquivo fantasma que se escabulle por las encrucijadas, paz que baja del cielo, blancor de cal que ilumina los rincones más íntimos, puertas pequeñas y bajas que, abiertas, dan paso al patio enjardinado y con fuentes de un agua muda» (108). El desplazamiento físico da lugar a un movimiento interior, en la memoria.

Lo antes tenue alcanza lucidez cuando el viajero regresa y posa la vista; sin embargo, la empresa es desgarradora: «La visión que se tiene de España después de cuarenta y siete años de ausencia es la de que se ha transformado, pasando de ser el país bello, pero de vida dura y de recursos limitados, a ser el más ardiente y hondo, el más pintoresco, el de más sabor de Europa» (68), explica el cronista. Es la imagen de un lugar diferente al de la niñez, el resultado del periplo de «un resucitado que vuelve y encuentra invisible su pequeño mundo, destruido por la acción del tiempo» (78).

Para el lector, el cambio podría parecer favorable, alentador; para la sensibilidad de Marín Cañas, lo nuevo entraña, con frecuencia, males y distorsiones. Un poco a la manera de Fernández Guardia, el narrador está convencido de que «en el siglo de exasperante materialismo, de frío progreso, en que no hay nada digno de respeto para el pico del demoledor, ni cosa para cuya hechura no existe una horrible máquina de patente, es empresa muy ardua dar con un pueblo virgen aún de la moderna fiebre destructora $»^{5}$.

La travesía empieza con la primavera. El primer relato sitúa los sucesos - en particular, el paso por el Estrecho- en una noche de abril (18); con todo y esto, los primeros hallazgos del viajero establecen una paradoja: «El luto es una nota permanente por las calles empedradas de los pueblos», aclara Marín Cañas, «reviste la

${ }_{5}^{5}$ Ricardo Fernández Guardia, «Sevilla» en Hojarasca (1894) (San José: Editorial de la Universidad Estatal a Distancia, 2004) 101. 
dimensión de un culto nacional» (13). El título alude a la dualidad, «Vive la muerte» llama a esta crónica. No se trata tan sólo de que los viejos compañeros de aula no puedan visitarse ya - han caído en la Guerra civil, ora en sus tierras, ora en el exilio, como el historiador cordobés Antonio Jaén-Morente-; se trata de un asunto más complejo todavía: recuperar el pasado parece empresa imposible.

Con esta serie de crónicas, publicadas por ocasión primera en el periódico La Nación, de Costa Rica, a modo de entregas, José Marín Cañas pretende mostrar cómo España se desgarra entre los bienes y la filosofía de sus orígenes y los ajetreos de la actualidad. El «milagro español» supone un objeto de estudio para el narrador, su escrutinio señala las aristas tenebrosas de este proceso de cambio económico y social; pesan en el escritor los enigmas y aprendizajes de juventud, la tesis de que lo sencillo por práctico vale tanto más.

Juventud vivida a medio camino entre la península y el istmo. De padres españoles, Marín Cañas nació en Costa Rica en 1904, pocos años después y en la misma calle josefina que el poeta Julián Marchena. En Valses nobles y sentimentales, sus memorias y un espléndido viaje por la Costa Rica de principios del siglo XX, refiere algunos de los atributos de su padre, un español terco y trabajador, que vino a hacer la América y volvió al pueblo natal por su joven prometida; de vuelta, fundó un almacén y procreó a un niño inquieto que, al parecer, no serviría de mucho ${ }^{6}$.

En estas mismas páginas relata su primera andanza española, un periodo de estudios durante la adolescencia; un plazo de sólo dos años, frustrado por lo demás puesto que el regreso fue urgente, pobre y sin títulos, que marcó una impronta en su carácter de joven y despertó amores. Pasiones que pueblan, noveladas, las páginas de sus primeros relatos, Lágrimas de acero (1929) y Tú, la imposible (1931); auténticas historias del desdén, donde los ambientes, personajes y el

$\overline{{ }^{6} J o s e ́ ~ M a r i ́ n ~ C a n ̃ a s, ~ V a l s e s ~ n o b l e s ~ y ~ s e n t i m e n t a l e s ~(S a n ~ J o s e ́: ~ E d i t o r i a l ~ C o s t a ~ R i c a, ~}$ 1981) 14. 
habla de Castilla acuden en el auxilio de este autor, cuyo primer verso aprendido procedía de un epitafio.

La melancolía le da más sentido al viaje; lejos de las guías para turistas, cercano al paseo literario del siglo XIX, Marín Cañas logra una hermosa visión de conjunto. Objeto raro entre las letras nacionales, parece probable que entre los escasos, éste sea el libro de viajes mejor logrado. Lo es por su tono, por el preciso conocimiento de la historia española que se demuestra, por lo original de las descripciones, por el aporte que les da a los géneros referenciales; en particular, al malogrado estilo periodístico. Probablemente, su infame expulsión de los recintos donde se enseña el periodismo, hoy pueda leerse como un síntoma de deterioro.

Este escritor, junto con León Pacheco, cultivó un estilo periodístico desprovisto de eufemismos léxicos como los que abundan en el discurso administrativo y político, pleno de usos cotidianos y combativo de las formas sencillas; un estilo que procede de los grandes difusores costarricenses como García Monge y Mario Sancho, pero que se anticipa y discute los mecanismos comunes y asentados de los medios masivos. Lo coloquial tiene cabida, pero lo coloquial arcaico, castizo y enraizado, lleno de significación e identidad.

En el caso de Marín Cañas, la crónica supone una base para la creación literaria, un fermento y no un objetivo. La empatía con el lector surge por causa de lo sugestivo de la atmósfera y de la anécdota; por todas las líneas, figura el autor, quien a pesar de las convenciones del género y las demandas del editor, ha preferido no ocultarse. La ironía delicada y el humorismo evitan con frecuencia que sus páginas se pierdan en ese «romántico» murmullo que le achacan con frecuencia. Su escritura no es anticuada, nace de los años bobos, y como estos, tiene presente la guerra, el desencanto y el dolor.

Los catálogos en torno a la obra de Marín Cañas deben ser revisados; la novedad que representó para su época es innegable. Tanto su ruptura con el costumbrismo como la incomprensión que lo rodeó —-Marín el imposible lo apodaban — ofrecen indicios acerca de 
sus condiciones de renovador ${ }^{7}$. El énfasis en la ciudad, en los personajes calamitosos y en los problemas derivados del liberalismo lo sitúan como una figura clave en el desarrollo de la literatura costarricense, pese de la magra recepción de sus escritos.

Los bigardos del ron (1929), El infierno verde (1935) y Pedro Arnáez (1942) refieren historias de desamparo y fracaso; los personajes inadaptados y esperpénticos emergen como resultado de la crónica, suponen un testimonio de la realidad de las calles, del Chaco y del agro centroamericano; en suma, del continente. Estos relatos así como otros escritos por Marín Cañas acuden a un género que por realista ofrece la posibilidad de lo poético ${ }^{8}$. Como autor, Marín Cañas demuestra una lograda conciencia panhispanista. Tierra de conejos (1971) participa, como una pieza más, de este modelo de escritura. La visión de España conlleva un doble propósito: hacer literatura y comprender; más que la península, se levanta ante nosotros el sueño de un escritor.

\section{Fábricas y paisaje: herencia de España}

En el recorrido de Marín Cañas, el itinerario por la geografía cede su lugar a una exploración. Según el autor lo propone, allí donde los turistas observan piedra y argamasa, el viajero desentierra el recuerdo de sus propios pasos. Ante ese panorama, desplazarse por una región equivale a transitar por el tiempo, a recuperar la memoria. Así, los atributos del entorno y los edificios adquieren un simbolismo preciso; naturaleza y hombre han forjado una cultura. El viajero se impone entonces la tarea de capturar el sentido de esos principios.

Los recintos, las riveras y masas de sólida roca delimitan una carta sentida, una suerte de mapa donde las finas líneas y las rúbricas hacen las veces de botaduras. El cuerpo de una nación herida por los eventos de la historia, pleno de cicatrices y enmiendas. En cada pasaje

\footnotetext{
${ }^{7}$ Ver prólogo de Alberto Cañas a Valses nobles y sentimentales (1981).

${ }^{8}$ Ver prólogo de Carlos Rafael Duverrán a Los bigardos del ron (San José: Editorial Costa Rica, 1978).
} 
del plano, el caminante vislumbra palimpsestos, acciones furtivas, nombres olvidados. Sin embargo, nada lo confunde; el paso y la caricia conducen hacia la claridad, hacia el ruido de la fuente, hacia el cuerpo amado.

\section{Las murallas}

Por donde vague su mirada, el cronista descubre un mundo áspero y mustio; lumbre que calcina, por doquier, las ciudades recuerdan fortalezas. Esos ríos mansos que contempla fueron alguna vez obstáculo, sirvieron como límite etéreo entre el horror y la calma. Para el visitante, resulta imposible no descifrar un pasado de gesta, caballo y espada en el ambiente. Esta justa impresión no nace a causa de los edificios; éstos tan sólo la alimentan, la tornan concreta; algo subyace, existe un aroma que impera, el fragor de la naturaleza; la guerra prevalece, incluso en los tiempos blandos.

En verdad, se trata de un asunto telúrico; mientras el viajero avanza en coche hacia Granada, sube por «los acantilados, que hacen de España un fuerte, a la manera de un castillo, construido sobre una mesa seca, que fue parda en los años en que no había embalses» (37). La Sierra Nevada constituye, por sí sola, la más tremenda muralla; sus cumbres blancas resguardan la esbelta capital provinciana. Cada cortijo ocupa la cúspide de un otero; el español construye en la cima, explica Marín Cañas, porque trae en la masa de la sangre el estar alerta contra la invasión del moro (40).

El carácter de la comunidad guarda un vínculo con las calidades del medio; España es a los españoles lo que cuerpo al alma. La feroz sobriedad del monte y del muro sirve de coraza para un interior tenue y dispuesto. El español es seco, pero amistoso (225), indica el narrador. En este sentido, la Alhambra resume y expresa tal dualidad: «Toda la sencillez y austeridad de la Alcazaba, muro castrense que la circunda, evitando la irrupción de enemigos ayer y de miradas curiosas hoy, se torna en sensual búsqueda del adorno en el interior» (48). 
Las claves halladas ante el monumento se transforman en indicios del temperamento ibérico; a modo de alegoría, señala el escritor que «si bien la Alcazaba está dispuesta para la guerra, el interior de los palacios está dispuesto para el amor» (48), y que «todo lo sencillo que es el edificio por fuera, medio cubierto a los ojos del transeúnte por los altos muros de la Alcazaba, tiene de pasional por adentro» (52). Sin embargo, el español —vástago de fenicios, germanos, latinos y moros, pueblos guerreros - es hijo eterno de la suspicacia.

Mientras recorre un trecho en tren, el escritor se pregunta « ¿A qué se debe el que las vías españolas sean más anchas que las del resto de Europa? Se debe a que España, para evitar en lo posible futuras invasiones de los franceses, no adoptó la vía ancha de ellos, sino que la hizo aún más, para que los coches de la vecina, si se lanzaban a repetir el napoleónico 1808 catastrófico, se encontraran, por lo menos, con una dificultad» (93).

\section{Las iglesias}

El vigor con que se responde a las amenazas y la reticencia ante el mundo devienen en contemplación; la intimidad de los templos y altares convoca la tranquilidad y adormece el recelo. Ante el Monasterio de San Lorenzo de El Escorial, nuestro autor reflexiona sobre los propósitos de Felipe II, acerca de su afán por hacer del Imperio una iglesia (189). Próximo al pensamiento de Unamuno y Lanza, está convencido de que España prefiere sentir a pensar; en esta actitud se oculta la simiente de su catolicidad, de su espíritu trágico (186).

«¿De dónde salió aquel monarca, cuya alma estaba atravesada por el tránsito del dolor humano y hacia la divina altura? ¿Quién sopló sobre su gorguera el consejo de acercarse al Creador haciéndole un templo, monasterio, abadía y cuarto humilde para él?» (182), se pregunta. El talante religioso de la obra alcanza mayor dramatismo si se lo considera bajo sus circunstancias, a saber, el instante climático de la obra de cruz y espada. En el vértice de la caída, el sabio rey 
presiente la muerte y procura permanecer. La fe insoslayable, la fe española, no supone confianza sino angustia.

"Azorín, en Castilla, escribe su más alto pensamiento:

«¡Eternidad, insondable eternidad del dolor! Progresará maravillosamente la especie humana; se realizarán las más fecundas transformaciones. Junto a un balcón, en una ciudad, en una casa, siempre habrá un hombre con la cabeza, meditadora y triste, reclinada en la mano. No le podrán quitar el dolorido sentir». Así habló Garcilaso. Así actuó, de primero en España, el taciturno monarca" (185-186), resuelve Marín Cañas. Poblado de iglesias, conventos y capillas, el paisaje del interior se colma de sentires, tan altos como catedrales.

\section{Las tumbas y los arcones}

«La muerte en mármol es un adorable sueño, un quieto cerrar los ojos, un permanecer inmóvil, despojado todo esto del verdadero horror del término» (62), describe Marín Cañas las esculturas que, en la Capilla Real de Granada, rememoran a los Católicos. A su vista, la cripta donde descansan Isabel, Fernando, Felipe El Hermoso y Juana más que una sepultura — nada queda en ésta — implica una señal: los cuatro sarcófagos esconden en sus trazos la línea de proa de un barco. Ansia y amor los arrojan hacia la historia; sus tumbas son baúles, donde el pasado descansa impoluto; naves, que transitan por densos siglos.

«Caminar por España es trotar por cementerios de gloria y huesos de gesta, levitarse hacia cornucopias apolilladas, techos infinitos, artesonados que los años pudrieron y ahora huelen a malva, mortandad e incienso». Continúa el viajero: «España es un cúmulo de empresas alocadas y bárbaras que dejó en las memorias de su gente un reguero interminable de héroes y de mártires a los que continuamente se les está cantando un réquiem silencioso» (14). Allí, en esa España, se deduce entonces, morir equivale a adquirir una existencia más profunda y limpia. 
La muerte no es tal, cuando sus objetos roídos se convierten en tesoros de la memoria, cuando los muebles antiguos, la cama de los abuelos, la consola de la tía y el espejo, todos al unísono, alcanzan la virtud de cristal y nos ofrecen un retrato roto de la patria. La historia se oye por doquier cuando se abren estos arcones, cuando se los visita y escucha; quizá por esto, durante su visita a la Alhambra, el escritor teme caer bajo el golpe del yatagán, al mirar con malicia hacia los aposentos de la favorita, en pos de odaliscas.

\section{Palacios, baños y plazas}

El legado material del pueblo español implica, a la vez, legado moral. Su variedad y riqueza brindan un certero informe acerca de lo heterogéneo de las raíces. El patrimonio morisco se conserva porque recubre una enseñanza de índole filosófica, una ética. Marín Cañas explica al lector la naturaleza de ésta: «la Alhambra no es un templo, sino un palacio, que no se hizo para pensar en Alá, ni para que el muezín cante su rezo, sino para vivir la vida, para gozar de los encantos de la creación, para beber con sibaritismo de raza todo el duende que encierra el enigma del sexo, para calmar la gran sed del desierto, absorber el trasudar del paisaje y del río, de los pinares, de la floresta» (46).

Entregadas las llaves de la ciudad a los católicos, el español penetró la sabiduría mudéjar y la amó. El escritor costarricense se sorprende: los edificios del derrotado acaban, es norma en Occidente, trastocados en ruinas. Sin embargo, en la península, no existen como añicos ni cenizas; por el contrario, siguen vivos; vivos porque su significado sigue vigente (54). Pasión por la vida, al modo de las Mil y una noches, es la lección aprendida. Al poner pie en el Museo de Romero de Torres, el cronista ingresa en la alcoba del pecado, en la decadencia del califato; un pintor español que toma por propias las imágenes de esos cuerpos morenos y lánguidos (113).

El otro ocioso placer se ha heredado de los romanos, quienes con sus termas enseñan cómo el baño más que una práctica ordinaria supone un ritual; en consecuencia, una actividad ajena al vértigo de 
los horarios (51). De entre gitanos, y en plazas, las ferias adquieren una dimensión particular; en el baile «la hembra se retuerce en una callado dolor de amor, en una desesperación íntima, sin reproches ni promesas» (57); «a los reproches de él, contesta ella con dulzura y ritmo y se le encandilan los ojos, y se enfurecen las caderas y se trenzan las piernas, pero ella está envuelta siempre en el aire y sólo el aire la toca» (97).

Durante las festividades en Sevilla, las plazas y calles huelen a «carne de membrillo, turrones de Jirona, pasta café tierno de almendras molidas, huevos, miel y gloria; turrones de estilo alicantino, envueltos en pan de hostia, blanco del azúcar y veteado con almendras, para los que se hace imprescindible tener unos dientes auténticos» (83), según comenta el narrador. Los licores dulces y amargos colman la convivencia; cientos son los que se sostienen, de ebrios, tan sólo con la mirada.

\section{La Mancha y los libros}

La travesía por España acaba por conducir al viajero al centro de lo castellano; para él, una parte esencial de lo español, pero no lo español por antonomasia, como se infiere de lo dicho hasta aquí. La Mancha «es inmensa, polvorosa e ilímite. Solamente el sol marca sus fronteras por el este y por el oeste. Lo demás es igual, tercamente lejana, con pequeños oteros y blancos molinos rotos» (130); es lo amplio y abierto, la promesa de un relato lleno de aventuras; no lo reacio.

Su paisaje figura en los libros, se lo lee en las páginas, no se contempla: «Los molinos, pesadamente, dan vueltas tardas de cara a los horizontes. Uno de ellos, desde siglos, está con el aspa rota» (130). La lengua extiende sus dimensiones, la universaliza. La planitud de la Mancha equivale a la plenitud de lo humano, concluye (129). Avanzar por sus senderos da la oportunidad de emprender un auténtico paseo literario; cuando el escritor costarricense se refiere a ésta, lo hace con lenguaje poético. 
Max Jiménez describió la geografía de España en unos cuantos versos de Sonaja (Madrid, 1930): «El Dios de todo ritmo / al modelar la tierra, / en ti contrajo el ceño / porque vio en el futuro / tu desgraciada historia; / y quedaste rugosa, / como estuvo la frente, / la frente / del que todo lo puede» ${ }^{9}$. La imagen de las sierras y de la planicie se conjugan en la zona quijotesca. A modo de retrato, otorga semblante a los lugares; conviene facciones para los entornos y resalta el carácter de los elementos.

Según estos parámetros, habría que considerar las crónicas de José Marín Cañas como una especie de cartografía literaria, un recorrido por el cuerpo de la cultura hispana, por su vientre y redoma. El narrador no fija un punto sino un símbolo, cada una de sus visiones apunta hacia algo más profundo que lo evidente; más que las maravillas, lo atraen los enigmas, tesoros y claves; su periplo recorre la comprensión y el disfrute de un tiempo distante, ajeno a las circunstancias de la estricta actualidad.

\section{Emblemas e incógnitas: porvenir de España}

El paisaje español es vasto y diverso, nunca como un jardín; recuerda algo del desierto. En este entorno cargado de templos, figuras de mármol, plazas, ventas, acantilados y cementerios, Marín Cañas descubre dos bestias, dos emblemas. Para el cronista, el borrico y el toro ofrecen las variantes del temperamento y vida de la región, constituyen una zoología del sueño. No se trata de animales míticos ni exóticos; ambos tienen mucho de ordinario, de vida habitual; sin embargo, ocupan el sitio de la custodia, son los guardianes del pasado y el futuro, vigilan las puertas de la ciudad.

En sus conductas y en su relación con lo humano, estas simples bestias recuerdan al viajero los preceptos españoles, el compendio de las desgracias sufridas y las virtudes adquiridas. Como dos emblemas se yerguen a lo largo de la península; ambos ofrecen lecciones

${ }^{9}$ Max Jiménez, «España» en Obra literaria (San José: Stvdivm, 1982) 177. 
imprescindibles acerca de lo que la nación fue y será. Los cambios en las costumbres bien podrían hacerlos desaparecer; no obstante, continúan marchando por los senderos, pertinaces como saber viejo.

\section{El borrico y los quehaceres}

Tras su paso por Nerja, pueblecito de sus padres, Marín Cañas se encuentra con Roberto Saumells, un viejo amigo, y su esposa. Puesto que la anécdota es breve, la resumo: la pareja y el escritor comen y discuten sobre los sucesos de París, la revuelta estudiantil del 68. Al final de una larga plática y a manera de despedida e invitación para un nuevo encuentro, el catedrático español afirma: «-Tenemos una casa en Valladolid, con alberca y burro» (24). La frase impresiona al costarricense; por encima de la hospitalidad, lo deslumbra la última palabra: burro.

Cavila entonces: «Con una larga curiosidad, con una interminable ternura, había descubierto — no se puede pensar una idea más sencilla - que en los caminos españoles, en los pueblos, por sus calles retorcidas y estrechas, había una nota de profunda ternura y de honda filosofía: los borricos, cuya estampa, a la que no estamos acostumbrados los de media América, me había causado una agradable sorpresa» (25). Para el escritor, esta bestia de trabajo personifica la paciencia, la serenidad y la bondad sin límites; en síntesis, encarna los valores opuestos a la actualidad, es el «antimundo».

El viaje hacia lo perdido, permite al narrador establecer un balance entre el pasado y el presente, identificar los cambios, las mejoras y las fallas. Marín Cañas advierte que los españoles, en particular los madrileños, corren el riesgo de malograr el ritmo de vida que les viene de antaño. «La ciudad ahora se angustia por tomar el autobús que pasa» (137). El milagro español convirtió a Madrid en foco de industria, en urbe, en apuro (138). Sólo en el viejo Madrid se respira (140); o en Barcelona, donde el trabajo y la prisa no marchan paralelos (207). 
Afirma, incluso, en tono profético: «Pasarán años por España, Madrid llegará a los diez millones, la ciudad se volverá ciclópea, su tráfico superará al de Nueva York y el desarrollo de sus fábricas ahogará a los madrileños, pero nunca, por los siglos, nunca Madrid volverá a tener aquella calle de Alcalá de las cinco de la tarde, la hora mágica, ingrávida y repuntante, en la que todas las guapas de todos los barrios de la capital de España se volcaban sobre la amplia avenida para lucir la gracia de su palmito, con la que Dios les había adornado la vida» (134). El ritmo de la máquina amenaza el ocio, el buen vivir (135).

Antes que Marín Cañas, otro viajero incansable, Mario Sancho, anunciaba ese declive en una carta a Ricardo Fernández Guardia: «Madrid, tengo que decirte francamente, que aunque me gustó por el carácter placentero de las gentes, por sus parques y por su Prado sobre todo, es la ciudad de España que menos impresión me hizo. Y es que como ciudad antigua tiene ya pocas cosas, a fuerza de derribos y modernización, que la hagan interesante por ese lado, y como ciudad moderna resulta algo provincial comparada a Nueva York, Londres, París y otras grandes capitales» ${ }^{10}$.

Al lado de la «calma faraónica» de la que habla Ortega y Gasset como medicamento contra el espasmo de lo moderno, conviene la constancia y el esfuerzo del labrador. «España fue la primera potencia del mundo, pero lo fue por su sangre aventurera y su idealismo delirante. Que por el trabajo y el empeño, al caminar que iba no hubiera sido nada» (142). Si en el pasado se sobrepuso el sueño; los nuevos tiempos imponen disciplina y labranza, no vértigo; paciencia en lugar de premura. Los motores de la industria, afirma el viajero, no deben sustituir las costumbres y maneras de vivir; «El español no es un financista, pero sí un senequista», concluye Marín Cañas

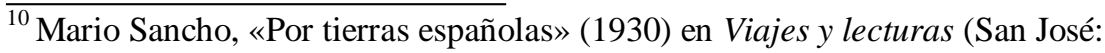

Editorial Costa Rica, 1972) 132. 


\section{El toro y las encrucijadas}

En una crónica titulada «Tres cruces hay en la arena», Marín Cañas se refiere a la figura del toro, pues encuentra en ésta un breviario de filosofía ibérica. Para él, el toro «es, en suma, el espíritu confuso de un pueblo que se encara con el destino, que desafía a Dios, que se humilla en el templo tembloroso y blasfema y se ahoga en su sangre y en su incienso» (149). Justo al lado del estoicismo, el narrador sitúa a la entereza como la otra línea básica del temperamento español; más allá de la espera prudente, se requiere, para resolver ciertos trances, del coraje.

En «La verdad y el artificio», crónica dedicada a la tauromaquia como metáfora de lo peninsular, el viajero hace recuento de los instantes de confrontación entre hombre y bestia. Este juego, un juego con la muerte - como lo define el autor-, supone tres etapas; requiere, por consiguiente, de tres actitudes: aguantar, templar y mandar. La suma deviene en un movimiento integral, pleno. Ya Darío había descrito cómo durante la corrida, el español celebra el retorno a la fiereza primitiva, a la forma más elemental del valor ${ }^{11}$.

«Aguantar es no moverse. Es no huir. Es no acobardarse», nos aclara Marín Cañas. «Ese valor seco es de la raza. Un valor sin ditirambos ni vistosidad. Es el mismo que quemó las naves. El mismo que empujó a Alvarado. Como Balboa cargó las barcas para tramontar la sierra». Igual al que escribió en Alicante: «La espero sin jactancia, porque nunca es alegre morir a mi edad, pero sin protesta»" (155156). La segunda actitud, templar, implica «urgir al espíritu para afrontar las situaciones graves de la vida, para actuar en el momento crucial de la suerte, no cuando viene el toro ni cuando se va, sino cuando está» (157).

Mandar es enviar con imperio al animal fuera de la suerte (158). En «Cuatro asientos de Barrera», el cronista culmina sus meditaciones acerca del genio español; desde su perspectiva, tras

${ }^{11}$ Ver Rubén Darío, «¡Toros!» (1899), Roberto Yanhi (Ed.), Prosa modernista hispanoamericana: antología (Madrid: Alianza, 1974) 95. 
siglos de aventura en ultramar, el habitante de la península ha logrado entender «el hecho enrevesado y truculento de que ellos suspiraban por irse de la tierra, del pueblo y de la vega, mientras que los que antes se habían ido suspiraban por volver, aunque fuera a tocar sólo el alcornoque que crecía en los años de la partida junto a la ermita» (144).

Los tres momentos de la plaza resultan análogos con tres procesos profundos de la historia de España: soportar, examinar y hacer constituyen trances del devenir nacional; no es sino ahora que "Los españoles —ipor fin! — han comenzado la conquista de España" (144), que encaran al destino y lo dominan. "Debajo del slogan turístico de que «España es diferente» hay toda una filosofía nacional descrita, porque «España es diferente» al resto del mundo, que es lo que intenta decir, pero es «diferente» a como era" (143), anota el viajero a modo de conclusión.

\section{Epílogo}

Concluida la lectura, como antes llegó a fin la travesía, podría preguntarse el lector de Tierra de conejos por el español; en las crónicas se remite a sus ambientes, a sus sitios de atractivo, a sus hitos, a su filosofía y dilemas, pero acerca del español parece decirse poco. Bien a las claras, Marín Cañas traza con sus relatos y anécdotas un firme retrato de las costumbres e ideas, un retrato que obedece a las circunstancias del viajero, a sus expectativas. La obra, en su unidad, prefiere pasar por alto los casos concretos; según se sugiere, lo español está por doquier en la península; en tanto que el español específico apenas regresa a su tierra. 